\title{
Identification of key miRNAs and genes for mouse retinal development using a linear model
}

\author{
YISHEN WANG $^{1}$, XIAO WANG ${ }^{1}$, YUKANG JIANG $^{2}$, RUYUAN LIU ${ }^{1}$, DI CAO ${ }^{1}$, JIANYING PAN ${ }^{1}$ and YAN LUO $^{1}$ \\ ${ }^{1}$ State Key Laboratory of Ophthalmology, Image Reading Center, Zhongshan Ophthalmic Center, Sun Yat-Sen University, \\ Guangzhou, Guangdong 510060; ${ }^{2}$ Department of Statistical Science, School of Mathematics, \\ Southern China Research Center of Statistical Science, Sun Yat-Sen University, Guangzhou, Guangdong 51027, P.R. China
}

Received July 23, 2019; Accepted April 1, 2020

DOI: $10.3892 / \mathrm{mmr} .2020 .11082$

\begin{abstract}
MicroRNAs (miRNAs) are upstream regulators of gene expression and are involved in several biological processes. The purpose of the present study was to obtain a detailed spatiotemporal miRNA expression profile in mouse retina, to identify one or more miRNAs that are key to mouse retinal development and to investigate the roles and mechanisms of these miRNAs. The miRNA expression pattern of the developing mouse retina was acquired from Locked Nucleic Acid microarrays. Data were processed to identify differentially expressed miRNAs (DE-miRNAs) using the linear model in Python 3.6. Following bioinformatics analysis and reverse transcription-quantitative polymerase chain reaction validation, 8 miRNAs (miR-9-5p, miR-130a-3p, miR-92a-3p, miR-20a-5p, miR-93-5p, miR-9-3p, miR-709 and miR-124) were identified as key DE-miRNAs with low variability during mouse retinal development. Gene Ontology analysis revealed that the target genes of the DE-miRNAs were enriched in cellular metabolic processes. Kyoto Encyclopedia of Genes and Genomes analysis demonstrated that the target genes of the DE-miRNAs were significantly enriched in PI3K/AKT/mTOR, class O of forkhead box transcription factors, mitogen-activated protein kinase (MAPK), neurotrophin and transforming growth factor (TGF)- $\beta$ signaling, as well as focal adhesion and the axon guidance pathway. PI3K, AKT, PTEN, MAPK1, Son of Sevenless, sphingosine-1-phosphate receptor $1, \mathrm{BCL}-2 \mathrm{~L} 11$, TGF- $\beta$ receptor type $1 / 2$ and integrin $\alpha$ (ITGA)/ITGAB, which are key components of the aforementioned pathways and were revealed to be target genes of several of the DE-miRNAs. The present study used a linear model to identify several DE-miRNAs, as well as their target genes and associated pathways, which may serve crucial roles
\end{abstract}

Correspondence to: Dr Yan Luo, State Key Laboratory of Ophthalmology, Image Reading Center, Zhongshan Ophthalmic Center, Sun Yat-Sen University, 54 Xianlie South Road, Guangzhou, Guangdong 510060, P.R. China

E-mail: luoyan2@mail.sysu.edu.cn

Key words: miRNA, retinal development, microarray, linear model in mouse retinal development. Therefore, the results obtained in the present study may provide the groundwork for further experiments.

\section{Introduction}

MicroRNAs (miRNAs) are small, non-coding RNAs that are $\sim 22$ nucleotides in length. They serve important roles in regulating gene expression and are involved in a number of biological processes, including early development, vascular development $(1,2)$, cell proliferation, differentiation and apoptosis (3). miRNAs are encoded and transcribed as primary transcripts, which are subsequently cleaved by 2 enzymes, Drosha and Dicer, to produce mature miRNAs. As part of the RNA-induced silencing complex, miRNAs regulate gene expression post-transcriptionally by binding to target mRNAs. Several genes are involved in the regulation of eye development and miRNAs have been shown to act upstream of these genes $(4,5)$. A previous study revealed that miRNA dysregulation during mouse retinal development resulted in morphological and functional defects (6).

While several studies have investigated the roles of miRNA in cancer $(7,8)$, few have investigated their role in development. In addition, a limited number of studies have examined the expression pattern of miRNAs in the mammalian retina. Karali et al (9) analyzed the spatiotemporal localization of several miRNAs in mouse embryonic and postnatal retinas. Hackler et al (10) used microarrays to characterize the miRNA expression patterns in the mouse retina from embryonic day 15 to adulthood. However, the aforementioned studies focused on the expression patterns of specific miRNAs or obtained a global expression profile for a limited number of time-points.

In mice, the period between postnatal day 0 (P0) and postnatal day 21 (P21) is important for to retinal development, particularly neuron development and angiogenesis $(11,12)$. The aim of the present study was to gain a more detailed understanding of the postnatal miRNA expression pattern over several time-points and to identify the miRNAs required for mouse retinal development, using a linear model. The combination of bioinformatics analysis and microarray data allowed for the comprehensive analysis of the miRNA expression pattern. Initially, differentially expressed miRNAs (DE-miRNAs) associated with neuron development and angiogenesis were 
identified. The target genes of these miRNAs were subsequently predicted and pathway enrichment analysis was performed using Gene Ontology (GO) and the Kyoto Encyclopedia of Genes and Genomes (KEGG). Reverse-transcription quantitative polymerase chain reaction (RT-qPCR) was performed to validate the identified miRNAs. The present study identified critical miRNAs associated with mouse retinal development and investigated their biological functions and molecular interactions.

\section{Materials and methods}

Animals. C57BL/6J pregnant mice aged 6-8 weeks (32-40 g) were purchased from the Ophthalmic Animal Laboratory, Zhongshan Ophthalmic Center, Sun Yat-Sen University and housed in a pathogen-free environment with an average temperature of $20^{\circ} \mathrm{C}, 55 \%$ humidity and 12-h light/dark cycle with free access to food and water. The procedures for the care and use of the animals were approved by The Ethics Committee of the Sun Yat-Sen University Zhongshan Ophthalmic Center (ethical approval no. 2017-069). Institutional and governmental regulations concerning the ethical use of animals were followed. Animal health and behavior were monitored daily. Retinas from mice at P0, P1, P3, P4, P7, P8, P10, P14 and P21 were harvested and pooled. A total of 46 mice were used for the experiment and sacrifice was performed by cervical dislocation.

RNA extraction. Each sample consisted of 8-10 mixed retina tissues. Total RNA was isolated using TRIzol ${ }^{\circledR}$ (Invitrogen; Thermo Fisher Scientific, Inc.) and purified with the RNeasy Mini kit (Exiqon; Qiagen $\mathrm{GmbH}$ ), according to the manufacturer's protocol. RNA quality and quantity were measured using a spectrophotometer (ND-1000; NanoDrop Technologies; Thermo Fisher Scientific, Inc.). To determine the RNA integrity, the isolated RNA with loading buffer was loaded and electrophoresed on a $1 \%$ Tris-Acetate-EDTA agarose gel.

miRNA labeling and array hybridization. The miRCURY ${ }^{\mathrm{TM}}$ $\mathrm{Hy}^{\mathrm{TM}} / \mathrm{Hy}^{\mathrm{TM}}$ Power labeling kit (Exiqon; Qiagen $\mathrm{GmbH}$ ) was used for miRNA labeling, according to the manufacturer's protocol. The Hy $3^{\mathrm{TM}}$-labeled samples were subsequently hybridized on the miRCURYTM Locked Nucleic Acid Array (version 18.0; Exiqon; Qiagen $\mathrm{GmbH}$ ), according to the manufacturer's protocol. The resulting slides were scanned using the Axon GenePix 4000B microarray scanner (Molecular Devices, LLC).

Identification of key DE-miRNAs. The expression of each miRNA on microarrays at the developmental time-points of interest was analyzed using linear regression models. For each miRNA, time-points and their corresponding expression values were regarded as independent variable $\mathrm{x}$ and dependent variable $\mathrm{y}$, respectively, as follows:

$$
y_{i}=\beta_{0}+\beta_{1} x_{i}+\varepsilon_{i}
$$

Where $\beta_{0}, \beta_{1}$ and $\varepsilon_{i}$ represented the intercept, slope and error term, respectively. The aim was to find the estimated value $\hat{\beta}_{0}$ and $\hat{\beta}_{1}$ for the intercept and slope that would provide the best fit for all the time-points for each miRNA. In other words, the goal was to find the $\hat{\beta}_{0}$ and $\hat{\beta}_{1}$ values that minimized the sum of the squared error term $(Q)$ :

$$
\begin{gathered}
\mathrm{Q}\left(\beta_{0}, \beta_{1}\right)=\sum\left(y_{i}-\beta_{0}-\beta_{1} x_{i}\right)^{2} \\
Q\left(\beta_{0}, \beta_{1}\right)=\min _{\beta_{0}, \beta_{1}} Q\left(\beta_{0}, \beta_{1}\right)
\end{gathered}
$$

Using the least-squares approach, the intercept and slope of the fitted regression line of each miRNA were calculated. The greater the absolute value of the slope, the greater the change in miRNA expression during mouse retinal development. Since data from microarrays often have high variability, the linear model may not be appropriate for miRNAs with a high absolute value of the slope. Therefore, in order to reduce the false positive rate, the coefficient of determination $\left(R^{2}\right)$ of each regression line was calculated to evaluate the proportion of the variance:

$$
R^{2}=\frac{\left(\sum\left(x_{i}-\bar{x}\right)\left(y_{i}-\bar{y}\right)\right)^{2}}{\sum\left(x_{i}-\bar{x}\right)^{2} \sum\left(y_{i}-\bar{y}\right)^{2}}
$$

Where

$$
\bar{x}=\frac{1}{n} \sum x_{i} \quad \text { and } \quad \bar{y}=\frac{1}{n} \sum y_{i}
$$

The closer $R^{2}$ is to 1 , the better the estimated regression line is at explaining the relationship between $\mathrm{x}$ and $\mathrm{y}$. miRNAs with a $R^{2}>0.6$ were considered reliable. This implied that $\leq 60 \%$ of the variability between the 2 variables was accounted for by a linear regression model (Fig. 1). miRNAs with absolute values of the slopes in the top $1 \%$ and $R^{2}>0.6$ were considered to be the most essential miRNAs during mouse retinal development and were defined as DE-miRNAs.

Identifying the target genes of the DE-miRNAs. TargetScan (version 7.2) (13) and miRDB (version 6.0) (14), 2 miRNA target gene prediction databases that are continuously updated, were used to identify the target genes of the DE-miRNAs using the default parameters. In order to increase the accuracy of the results obtained, any gene that was predicted by both databases for a specific miRNA was considered as a target gene for that miRNA.

GO and KEGG pathway enrichment analyses. A GO term describes the functions of specific genes in terms of their associated biological processes, cellular components and molecular functions. GO enrichment analysis is used to identify which GO terms are enriched in a given gene set $(15,16)$. Based on the knowledge of molecular interactions, reactions and gene relation networks, potential target genes of interest were annotated in a collection of manually drawn pathway maps. The goal of KEGG pathway enrichment analysis is to determine the pathways in which a certain set of genes are over-represented (17). After the target genes were identified, GO and KEGG pathway enrichment analyses were performed using the online tool DAVID (version 6.8) $(18,19)$.

$R T-q P C R$. RT-qPCR analysis of the final filtered DE-miRNAs was performed. Total RNA from retinas was isolated and RNA quality and quantity were measured as described earlier. The RNA was reverse transcribed with a PrimeScript RT reagent kit (Takara Bio, Inc.) using specific primers for each miRNA and U6 was used as the reference (Bulge-Loop miRNA qPCR Primers; RiboBio, Co., Ltd.; the sequences are a commercial 

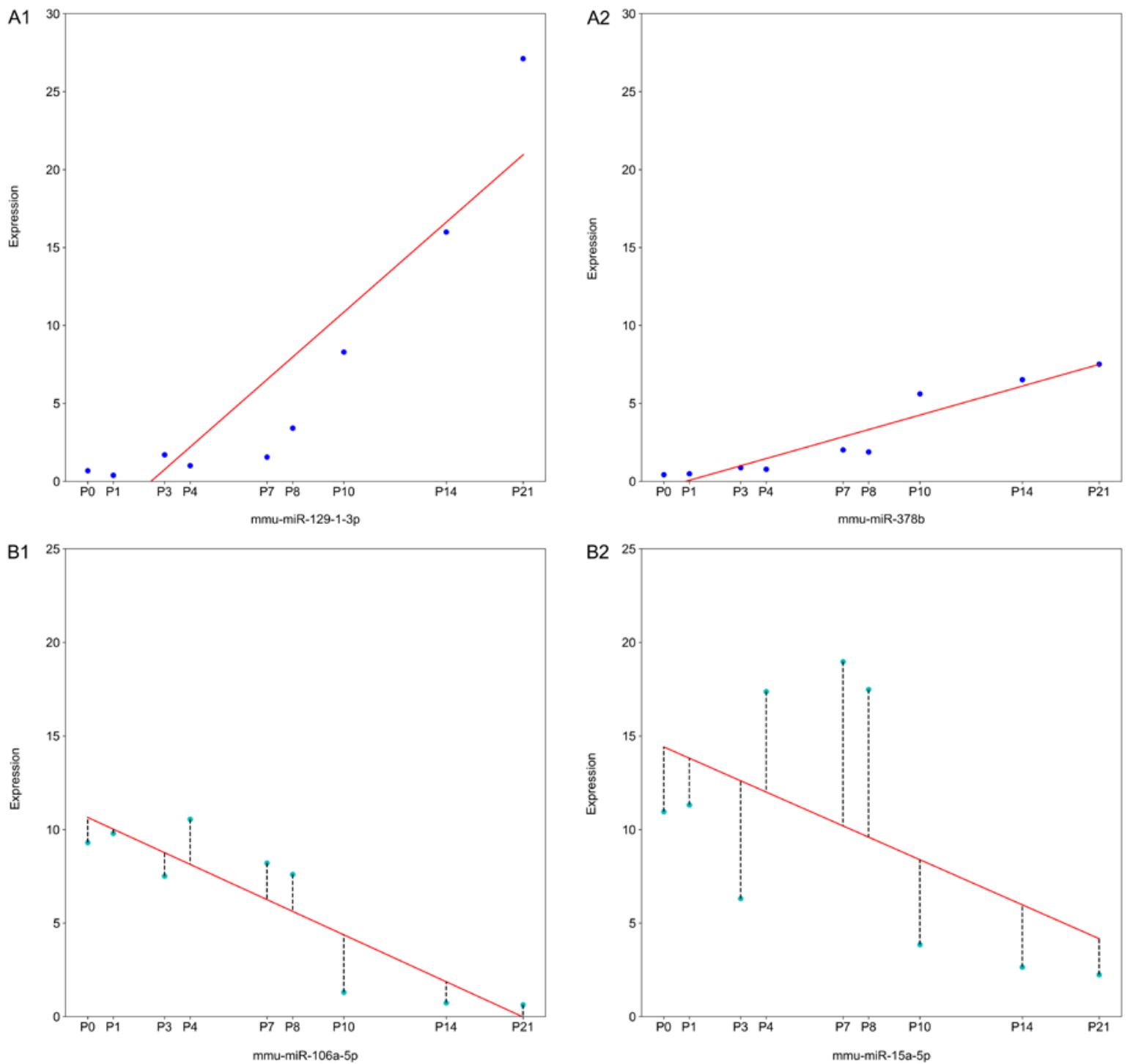

Figure 1. Demonstration of the miRNA linear regression model. The figure demonstrates how change and variability in expression were evaluated for each miRNA. (A) Using a similar $R^{2}$, the absolute value of the slope of mmu-miR-129-1-3p was greater than that of mmu-miR-378b, indicating that mmu-miR-129-1-3p exhibited a greater change in expression during development. (B) Using a similar slope value, the value of $R^{2}$ of mmu-miR-106a-5p was greater than that of mmu-miR-15a-5p, indicating that mmu-miR-106a-5p expression exhibited less variability and was therefore more reliable. miRNA/miR, microRNA; mmu, mouse.

secret). Real-time PCR was subsequently performed conducted on the resulting cDNA template using TB Green ${ }^{\mathrm{TM}}$ Premix Ex $\mathrm{Taq}^{\mathrm{TM}}$ II (Takara Bio, Inc.) on a StepOnePlus ${ }^{\mathrm{TM}}$ Real-Time PCR System (Applied Biosystems; Thermo Fisher Scientific, Inc.) using the following protocol: $95^{\circ} \mathrm{C}$ for $30 \mathrm{sec} ; 40$ cycles of $95^{\circ} \mathrm{C}$ for $10 \mathrm{sec}, 60^{\circ} \mathrm{C}$ for $20 \mathrm{sec}$, and $70^{\circ} \mathrm{C}$ for $1 \mathrm{sec}$. miRNA expression levels were quantified using the $2^{-\Delta \Delta C q}$ method and normalized to U6 levels (20). Efficiencies of qPCR reactions were also calculated by standard curve method (21).

Statistical analyses: The method of identifying DE-miRNAs using linear regression models has already been described. miRNA expression levels and efficiencies were calculated from the average of three independent RT-qPCR experiments. Linear regression models were also used to fit the RT-qPCR data. In enrichment of GO and KEGG pathway analyses, $\mathrm{P}<0.05$ was considered to indicate a statistically significant difference. All the data processing and figure generation were performed using Python. (Python Software Foundation;
Python Language Reference; version 3.6; https://www. python.org).

\section{Results}

Identification of key DE-miRNAs in mouse retinal development. The mean values of the concentration and OD 260/280 for the RNA samples were $1,156 \mathrm{ng} / \mu 1$ and a ratio of 2.02 , respectively, indicating that the RNA samples were acceptable for microarray hybridization. The microarray data discussed in the present study have been deposited in the Gene Expression Omnibus (GEO) and are accessible through GEO Series accession number GSE115581 (https://www.ncbi. nlm.nih.gov/geo/query/acc.cgi?acc=GSE115581). A total of 1,114 mouse miRNAs were identified and analyzed from the microarrays. The slope values for the majority of the miRNAs were equal or nearly equal to 0 , indicating that the expression of these miRNAs did not significantly change during mouse retinal development (Fig. 2). 


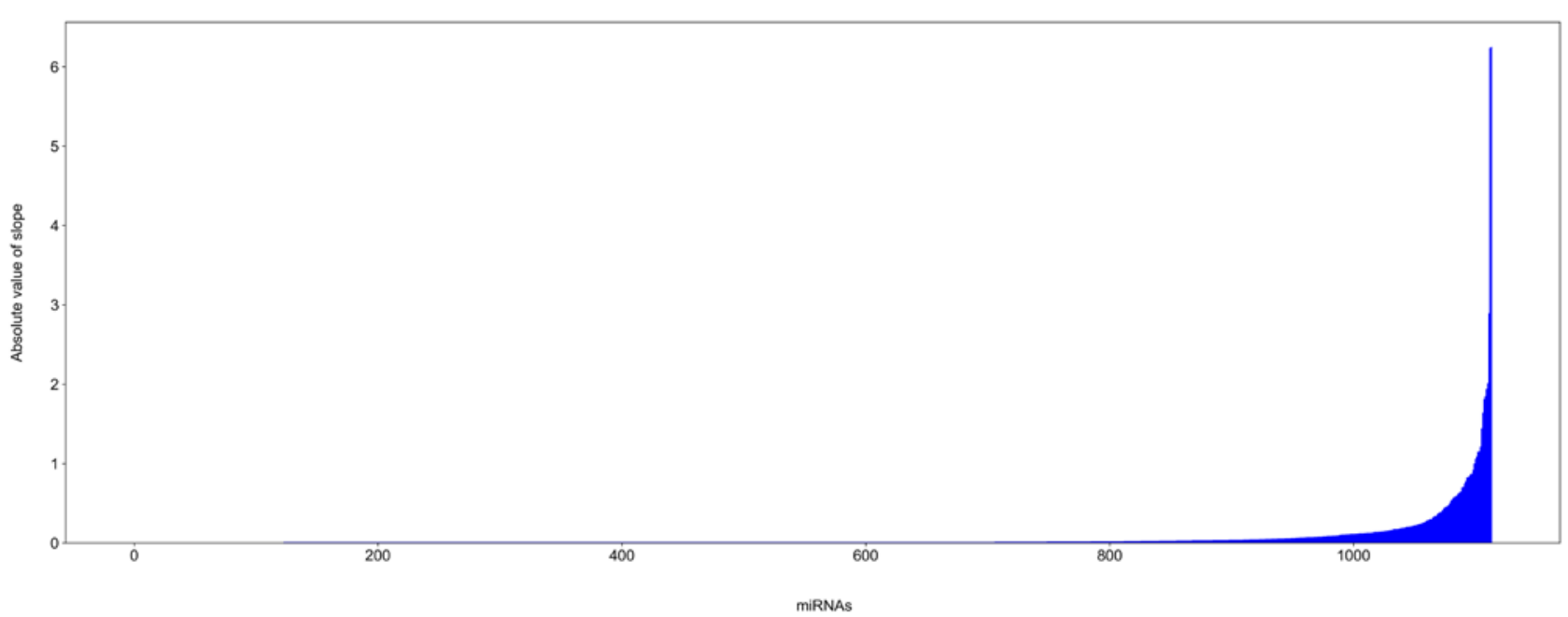

Figure 2. Graph of the absolute values of the slopes. The bar graph presents the distribution of the absolute values of the slopes of all mmu-miRNAs in ascending order. The horizontal axis represents the different miRNAs and the vertical axis represents the value of the slopes. mmu, mouse; miRNA, microRNA.

A change in slope value can be seen at the far right of the horizontal axis (Fig. 2). Using a top $1 \%$ cut-off, miRNAs with no significant trend were excluded. The $R^{2}$ of each identified miRNA was evaluated and miRNAs were considered to be DE-miRNAs if the absolute value of the slope was in the top $1 \%$ and $R^{2}>0.6$. Using this threshold, a total of 14 miRNAs were identified and included miR-709, miR-1839-3p, miR-9-5p, miR-130a-3p, miR-181a-5p, miR-181b-5p, miR-92a-3p, miR-20a-5p, miR-93-5p, miR-9-3p, miR-124-3p, miR-378a-3p, miR-129-1-3p and miR-125a-5p (Figs. 3 and 4).

Enrichment analyses of $G O$ and KEGG pathway. A target gene set was retrieved from TargetScan and miRDB for each DE-miRNA. After target genes had been retrieved, GO and KEGG enrichment analyses were performed through the DAVID online tool. With an adjusted $\mathrm{P}<0.05$, each gene set generated both a GO and a KEGG enrichment result. For biological processes, $\mathrm{GO}$ analysis results revealed that target genes of DE-miRNAs were enriched in cellular metabolic process-related terms (Table I).

KEGG pathway enrichment analysis indicated that target genes of DE-miRNAs were significantly enriched in development-related pathways, including PI3K/AKT/mTOR signaling, class $\mathrm{O}$ of forkhead box transcription factors (FOXO) signaling, mitogen-activated protein kinase (MAPK) signaling, neurotrophin signaling, transforming growth factor (TGF)- $\beta$ signaling, focal adhesion and axon guidance pathways (Table II). miR-1839-3p, miR-378a-3p, miR-129-1-3p and miR-125a-5p showed no significant enrichment associated with retinal development in KEGG analysis.

PI3K, AKT, PTEN, mitogen-activated protein kinase (MAPK)1, Son of Sevenless (SOS), sphingosine-1-phosphate receptor 1 (S1PR1), BCL2L11, TGF- $\beta$ receptor (TGFBR) $1 / 2$ and integrin $\alpha$ (ITGA)/ITGB are important components of the significantly enriched pathways. Each gene was predicted for several DE-miRNAs in the present study. PI3K/AKT were predicted as target genes of miR-130a-3p and miR-9-3p. SOS, S1PR1 and BCL2L11 were predicted as the target of miR-124. PTEN and MAPK1 were predicted as the target of miR-181a/b-5p, miR-92a-3p, miR-709 and miR-130a-3p.
TGFBR1/2 were predicted as target genes of miR-181a/b-5p, miR-130a-5p, miR-93-5p and miR-9-5p and ITGA/ITGB predicted for miR-9-3p, miR-124 and miR-92a-3p.

$R T-q P C R$ validation. $\mathrm{RT}$-qPCR was performed to validate the microarray results. The efficiencies calculated from the standard curves were all between 0.9 and 1.1 (Fig. 5), indicating that it was appropriate to use 2 as the base number for the $2^{-\Delta \Delta \mathrm{Cq}}$ method. The melt curves of the $10 \mathrm{DE}-\mathrm{miRNAs}$ exhibited only one peak at a similar temperature, indicating that the amplification was specific. Apart from miR-181a-5p and miR-181b-5p, the 8 remaining miRNAs exhibited a similar trend to the microarray results (Fig. 6).

\section{Discussion}

miRNAs regulate the expression of target genes and are involved in a number of cellular processes, including the cell cycle, self-renewal and differentiation. Tissue-specific and spatiotemporal changes in miRNA expression suggest that miRNAs are involved in the regulation of differentiation, development and maturation during mouse retinal development. Therefore, the present study filtered several key miRNAs according to the temporal characteristics of mouse retinal development.

In the field of genomics, the aim is to find the 'trend' or 'difference' among data sets. Previous studies often used an independent t-test or one-way analysis of variance (ANOVA) to compare 2 or more data sets. It is appropriate to use a t-test and ANOVA to process cross-sectional data when comparisons among experimental and control groups are performed at the same time and statistical results suggest an association between the data sets. The expression data of each miRNA during retinal development, however, were taken at successive time-points. Therefore, a t-test or ANOVA would not reflect the overall expression trend involving all time-points. For example, in a study conducted by Hackler et al (10), the expression change for each miRNA was defined as the difference between the maximum and minimum values among five timepoints using a t-test. Therefore, data on the three remaining 
Table I. Gene ontology analysis for the biological process of predicted target genes associated with retina development.

\begin{tabular}{|c|c|c|c|}
\hline miRNA & Term & $\begin{array}{l}\text { Gene } \\
\text { count }\end{array}$ & $\begin{array}{l}\text { Adjusted } \\
\text { P-value }^{\text {a }}\end{array}$ \\
\hline \multirow[t]{3}{*}{$\operatorname{miR}-9-5 p$} & $\begin{array}{c}\text { GO:0043161 proteasome-mediated ubiquitin-dependent } \\
\text { protein catabolic process }\end{array}$ & 21 & $8.37 \times 10^{-3}$ \\
\hline & GO:0036211 protein modification process & 96 & $8.98 \times 10^{-3}$ \\
\hline & GO:0006464 cellular protein modification process & 96 & $8.98 \times 10^{-3}$ \\
\hline \multirow[t]{3}{*}{ miR-130a-3p } & GO:0036211 protein modification process & 107 & $2.31 \times 10^{-7}$ \\
\hline & GO:0006464 cellular protein modification process & 107 & $2.31 \times 10^{-7}$ \\
\hline & GO:0010556 regulation of macromolecule biosynthetic process & 112 & $6.45 \times 10^{-6}$ \\
\hline \multirow[t]{3}{*}{$\operatorname{miR}-181 \mathrm{a} / \mathrm{b}-5 \mathrm{p}$} & ‘GO:0006351 transcription, DNA-templated’' & 129 & $5.97 \times 10^{-9}$ \\
\hline & GO:0006357 regulation of transcription from RNA polymerase II promoter & 88 & $3.98 \times 10^{-9}$ \\
\hline & GO:0051252 regulation of RNA metabolic process & 140 & $6.23 \times 10^{-9}$ \\
\hline \multirow[t]{3}{*}{ miR-93-5p } & GO:0010556 regulation of macromolecule biosynthetic process & 169 & $1.87 \times 10^{-8}$ \\
\hline & GO:0006357 regulation of transcription from RNA polymerase II promoter & 96 & $2.90 \times 10^{-8}$ \\
\hline & 'GO:0006351 transcription, DNA-templated' & 141 & $6.37 \times 10^{-8}$ \\
\hline \multirow[t]{3}{*}{$\operatorname{miR}-92 a-3 p$} & GO:0006464 cellular protein modification process & 97 & $4.68 \times 10^{-7}$ \\
\hline & GO:0036211 protein modification process & 97 & $4.68 \times 10^{-7}$ \\
\hline & GO:0006796 phosphate-containing compound metabolic process & 78 & $6.62 \times 10^{-8}$ \\
\hline \multirow[t]{3}{*}{$\operatorname{miR}-20 a-5 p$} & GO:0010556 regulation of macromolecule biosynthetic process & 169 & $6.83 \times 1^{0-12}$ \\
\hline & GO:0006357 regulation of transcription from RNA polymerase II promoter & 95 & $2.03 \times 10^{-11}$ \\
\hline & 'GO:0006351 transcription, DNA-templated' & 140 & $4.40 \times 10^{-11}$ \\
\hline \multirow[t]{3}{*}{$\operatorname{miR}-9-3 p$} & GO:0031325 positive regulation of cellular metabolic process & 87 & $3.67 \times 10^{-3}$ \\
\hline & GO:0010604 positive regulation of macromolecule metabolic process & 86 & $5.11 \times 10^{-3}$ \\
\hline & GO:0009893 positive regulation of metabolic process & 90 & $5.48 \times 10^{-3}$ \\
\hline \multirow[t]{3}{*}{ miR-124 } & GO:0006357 regulation of transcription from RNA polymerase II promoter & 113 & $2.51 \times 10^{-8}$ \\
\hline & GO:0007155 cell adhesion & 103 & $4.41 \times 10^{-8}$ \\
\hline & GO:0022610 biological adhesion & 103 & $4.57 \times 10^{-8}$ \\
\hline \multirow[t]{3}{*}{ miR-709 } & GO:0050839 cell adhesion molecule binding & 44 & $1.39 \times 10^{-8}$ \\
\hline & GO:0098632 protein binding involved in cell-cell adhesion & 33 & $3.48 \times 10^{-8}$ \\
\hline & GO:0098631 protein binding involved in cell adhesion & 33 & $5.24 \times 10^{-8}$ \\
\hline
\end{tabular}

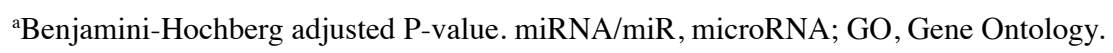

time-points were lost. In order to overcome the difficulty of identifying the 'trend' in the present study, linear regression models were used to analyze the expression of each miRNA at the developmental times. Slopes with a greater absolute value indicated a greater change in miRNA expression.

As the microarray data had high variability, the $R^{2}$ was used to evaluate the variance in miRNA expression. The closer the value of $R^{2}$ was to 1 , the better the linear regression fit the expression data. The miRNAs with high slope and $R^{2}$ values tended to have biological significance and were identified as DE-miRNAs. Subsequently, DE-miRNAs were screened for functional analysis.

Retinal vascular and neuron development are of great importance in the functionalization of the retina. Functionalization is a complex process with rapid changes in infant mice. Previous studies have reported that the blood plexus was almost completely absent in mice at P1 but became dense at P3. By P5, arterioles and venules had formed $(11,22)$. Research has demonstrated that the period between P0 and
P21 is critical for retinal neuron development and angiogenesis in mice $(11,12)$. To obtain a more detailed description of the miRNA expression profile in the mouse retina in the present study, a total of 9 developmental time-points between P0 and P21 were used, with increased sampling density at the earlier time-points.

The linear model used allowed all the developmental time-points of interest to be considered. The miRNAs with absolute values of the slope in the top $1 \%$ were selected for further analysis. Along with the evaluation of $R^{2}, \mathrm{GO}$ and KEGG analyses and RT-qPCR validation, 8 key DE-miRNAs were identified (Fig. 7). These were: miR-9-5p, miR-130a-3p, miR-92a-3p, miR-20a-5p, miR-93-5p, miR-9-3p, miR-709 and miR-124.

miR-124 and miR-9-5p/3p have been reported to be enriched in the mammalian retina $(9,23,24)$. The present study revealed that miR-124a-3p exhibited an increasing trend in both the microarray and RT-qPCR. Previous studies have revealed that miR-124 promoted the human brain tumor 


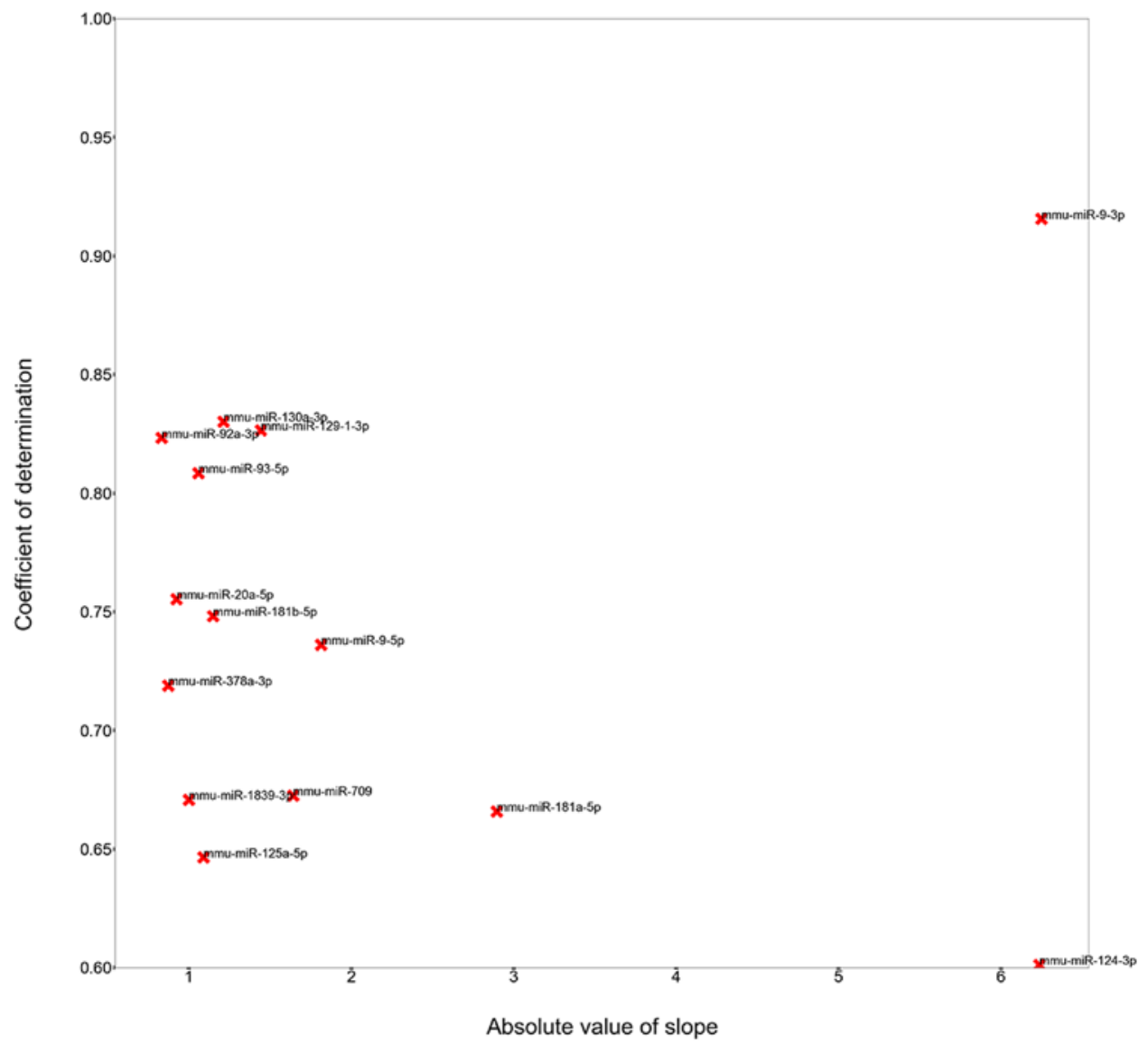

Figure 3. Absolute values of the slope and $R^{2}$ for the DE-miRNAs. The DE-miRNAs that had an absolute value of the slope in the top $1 \%$ and $R^{2}>0.6$ were included in the present study. The horizontal axis represents the absolute value of the slope and the vertical axis represents the value of $R^{2}$. miRNAs closer to the upper right corner exhibited greater changes in expression and less variability during development. DE, differentially expressed; miRNA/miR, microRNA; mmu, mouse.

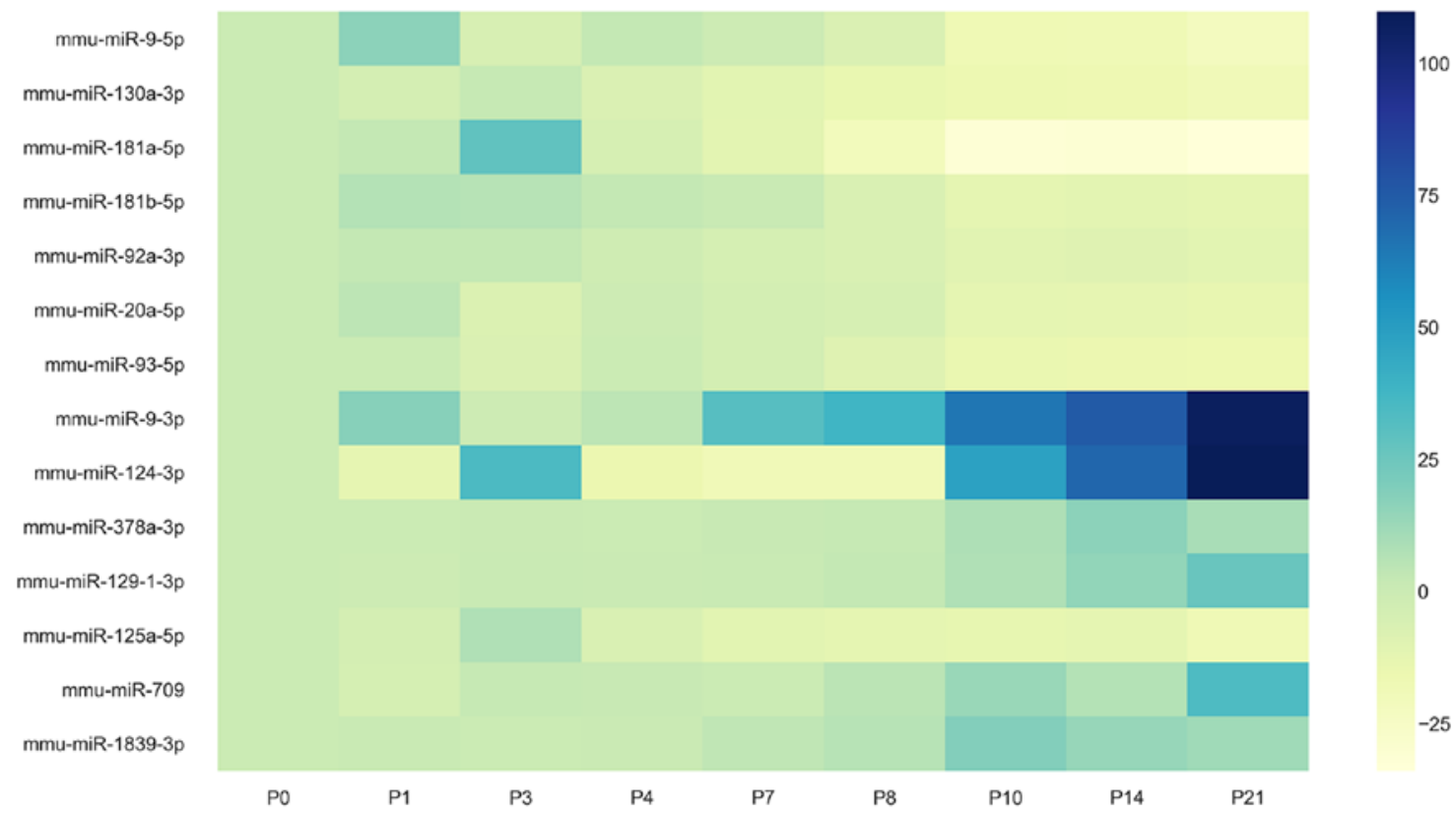

Figure 4. Heat-map of the DE-miRNAs. The heat-map revealed the expression trend of the 14 DE-miRNAs. The brighter the color in the grid, the greater the expression of the corresponding miRNA. DE, differentially expressed; miRNA/miR, microRNA; mmu, mouse.

growth and angiogenesis $(25,26)$. Additionally, miR-124 is required for normal retinal neuronal development in Xenopus and rats $(27,28)$.
A number of studies have considered miR-9-5p and miR-9-3p as a single combined entity $(29,30)$. miR-9/9*. Yoo et al (29) reported that miR-9/9* and miR-124 induce the 

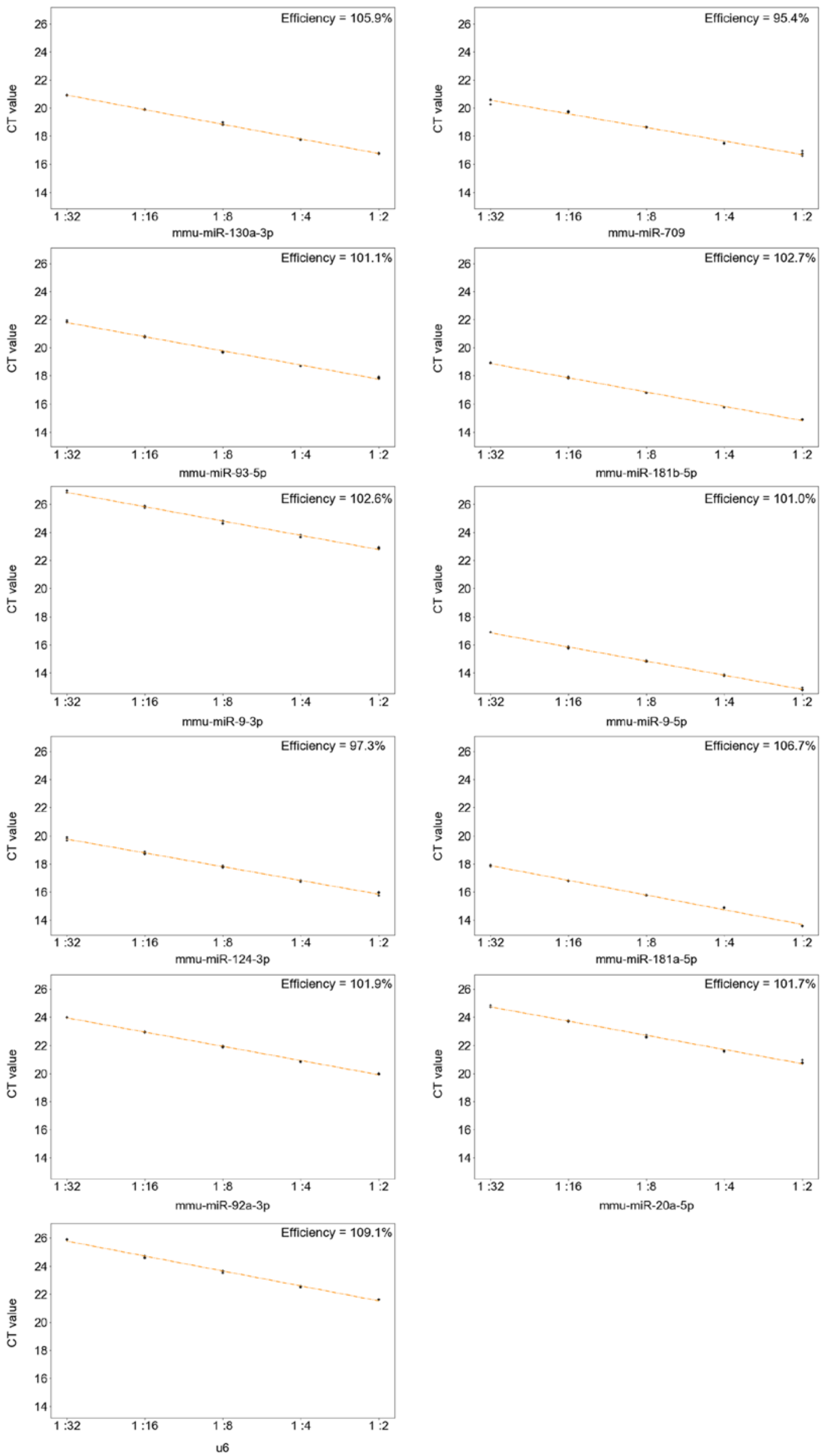

Figure 5. Efficiencies of the 10 miRNAs. The efficiencies were calculated from the standard curves of the DE-miRNAs and the internal reference gene U6. All the calculated efficiencies were between 0.9 and 1.1. DE, differentially expressed; miRNA/miR, microRNA; mmu, mouse; CT, cycle threshold. 
Table II. KEGG pathway analysis of predicted target genes associated with retina development.

\begin{tabular}{|c|c|c|c|c|}
\hline miRNA & Term & $\begin{array}{l}\text { Gene } \\
\text { count }\end{array}$ & $\begin{array}{l}\text { Adjusted } \\
\text { P-value }^{\mathrm{a}}\end{array}$ & Genes \\
\hline \multirow[t]{2}{*}{$\operatorname{miR}-9-5 p$} & Neurotrophin signaling pathway & 10 & $3.84 \times 10^{-2}$ & $\begin{array}{l}\text { 'MAP3K3, MAP } 3 K 1, \text { GSK3B, SORT1, NFKB1, } \\
\text { SHC1, MAPKAPK2, SHC2, MAP } 2 K 7, \text { ARHGDIA' }\end{array}$ \\
\hline & MAPK signaling pathway & 14 & $3.03 \times 10^{-2}$ & $\begin{array}{l}\text { 'MEF2C, RPS6KA4, MAP3K3, MAP } 3 K 1, T G F B R 1, \\
\text { TGFBR2, PDGFRB, CACNB2, NFKB1, MAPKAPK2, } \\
M A P 2 K 7, N F A T C 3, \text { STK3, ATF2' }\end{array}$ \\
\hline \multirow[t]{3}{*}{$\operatorname{miR}-130 a-3 p$} & TGF- $\beta$ signaling pathway & 9 & $3.92 \times 10^{-3}$ & $\begin{array}{l}\text { 'INHBB, ACVR2A, MAPK1,TNF, TGFBR2, } \\
\text { SMAD5, BMPR2,TGFB2, ACVR1' }\end{array}$ \\
\hline & mTOR signaling pathway & 7 & $1.65 \times 10^{-2}$ & $\begin{array}{l}\text { 'MAPK1,TNF, TSC1, PIK3CB, ULK2, } \\
\text { PRKAA1, PTEN' }\end{array}$ \\
\hline & FOXO signaling pathway & 9 & $4.32 \times 10^{-2}$ & $\begin{array}{l}\text { 'MAPK 1, S1PR1, PIK3CB,TGFBR2, PRKAA1, } \\
\text { PTEN, GADD45A, BCL2L11, TGFB2' }\end{array}$ \\
\hline \multirow[t]{3}{*}{$\operatorname{miR}-181 \mathrm{a} / \mathrm{b}-5 \mathrm{p}$} & FOXO signaling pathway & 12 & $5.37 \times 10^{-3}$ & $\begin{array}{l}\text { 'CCNB1, MAPK1, S1PR1, MAP } 2 K 1, \text { SOS1, } \\
\text { TGFBR1,NLK, GRM1, PTEN, SIRT1, } \\
\text { AKT3, BCL2L11' }\end{array}$ \\
\hline & mTOR signaling pathway & 7 & $2.30 \times 10^{-2}$ & $\begin{array}{l}\text { 'RPS6KA6, MAPK1, TNF, RPS6KB1, PTEN, } \\
\text { AKT3, DDIT4' }\end{array}$ \\
\hline & TGF- $\beta$ signaling pathway & 8 & $2.88 \times 10^{-2}$ & $\begin{array}{l}\text { 'MAPK1,TNF, E2F5, SMAD7, TGFBR1, } \\
\text { RPS6KB1, TGIF2, ACVR1C' }\end{array}$ \\
\hline miR-93-5p & Axon guidance & 13 & $1.49 \times 10^{-2}$ & $\begin{array}{l}\text { 'SEMA5A, EPHA5, PAK7, EPHA4, EPHA7, } \\
\text { LIMK1, CFL2, SEMA7A, DPYSL5, PPP3R1, } \\
\text { SEMA4B, DPYSL2, SRGAP1' }\end{array}$ \\
\hline \multirow[t]{2}{*}{$\operatorname{miR}-92 a-3 p$} & PI3K-Akt signaling pathway & 19 & $1.67 \times 10^{-4}$ & $\begin{array}{l}\text { 'IBSP, PHLPP2, PIK3CB, PTEN, COL5A1, } \\
\text { BCL2L11, CCNE2, TSC1, ITGA6, CHRM2, } \\
\text { ITGA5, ITGAV, COL27A1, ITGA8, CREB3L2, } \\
\text { COL1A2, PIK3CA, FASL, PRKAA2' }\end{array}$ \\
\hline & Focal adhesion & 14 & $7.07 \times 10^{-4}$ & $\begin{array}{l}\text { 'IBSP }, \text { PIK3CB, PPPIR12C, PTEN, COL5A1, } \\
\text { ITGA6,ITGA5,ITGAV,ITGA8, COL27A1, } \\
\text { COL1A2, PIK3CA, RAPIB, MAPK8' }\end{array}$ \\
\hline miR-20a-5p & Axon guidance & 13 & $1.57 \times 10^{-2}$ & $\begin{array}{l}\text { 'SEMA5A, EPHA5, PAK7, EPHA4, EPHA7, } \\
\text { LIMK1, CFL2, SEMA7A, DPYSL5, PPP3R1, } \\
\text { SEMA4B, DPYSL2, SRGAP1' }\end{array}$ \\
\hline $\operatorname{miR}-9-3 p$ & Axon guidance & 10 & $5.32 \times 10^{-2}$ & $\begin{array}{l}\text { 'LRRC4, DCC, GNAI2, PLXNA2, GNAI1, CFL2, } \\
\text { SEMA3A, SEMA4D, ITGB1, RASA1' }\end{array}$ \\
\hline \multirow[t]{2}{*}{ miR-124 } & Axon guidance & 14 & $2.95 \times 10^{-2}$ & $\begin{array}{l}\text { 'PLXNA3, NRP1, GNAI3, ROCK1, GNAI1, } \\
\text { PLXNB2, SLIT1, ITGB1,EPHA2, SEMA6A, } \\
\text { SEMA6D, UNC5D, NFATC2, SRGAP1' }\end{array}$ \\
\hline & Focal adhesion & 18 & $2.84 \times 10^{-2}$ & $\begin{array}{l}\text { 'CAV1, TLN1, COL4A1, ROCK1, ACTN4, PGF, } \\
\text { GRB2, ITGA3, ITGB1, FLNB, CRKL, CCND2, } \\
\text { SOS1, SOS2, ITGA7, SHC1, LAMC1, RAPGEF1' }\end{array}$ \\
\hline miR-709 & Axon guidance & 15 & $1.88 \times 10^{-4}$ & $\begin{array}{l}\text { 'PLXNA4, EFNB3, EFNA1, LIMK1, PLXNA2, } \\
\text { EFNB1, PAK6, NCK2, EPHA4, MAPK1, SEMA4G, } \\
\text { SEMA3F, ROBO2, PAK1, SRGAP2' }\end{array}$ \\
\hline
\end{tabular}

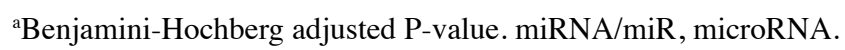

conversion of human fibroblasts into neurons. Other studies revealed that the 5' strand and 3' strand of miR-9 showed different effects. Sim et al (31) found that miR-9-3p, but not miR-9-5p, served an important role in hippocampal long-term potentiation in the adult mouse. $\operatorname{miR}-9-3 p$ and miR-9-5p were reported to serve key roles in neurogenesis (32). In the present study, miR-9-3p and miR-9-5p were analyzed separately and each showed significant expression trends with high $R^{2}$ values. 

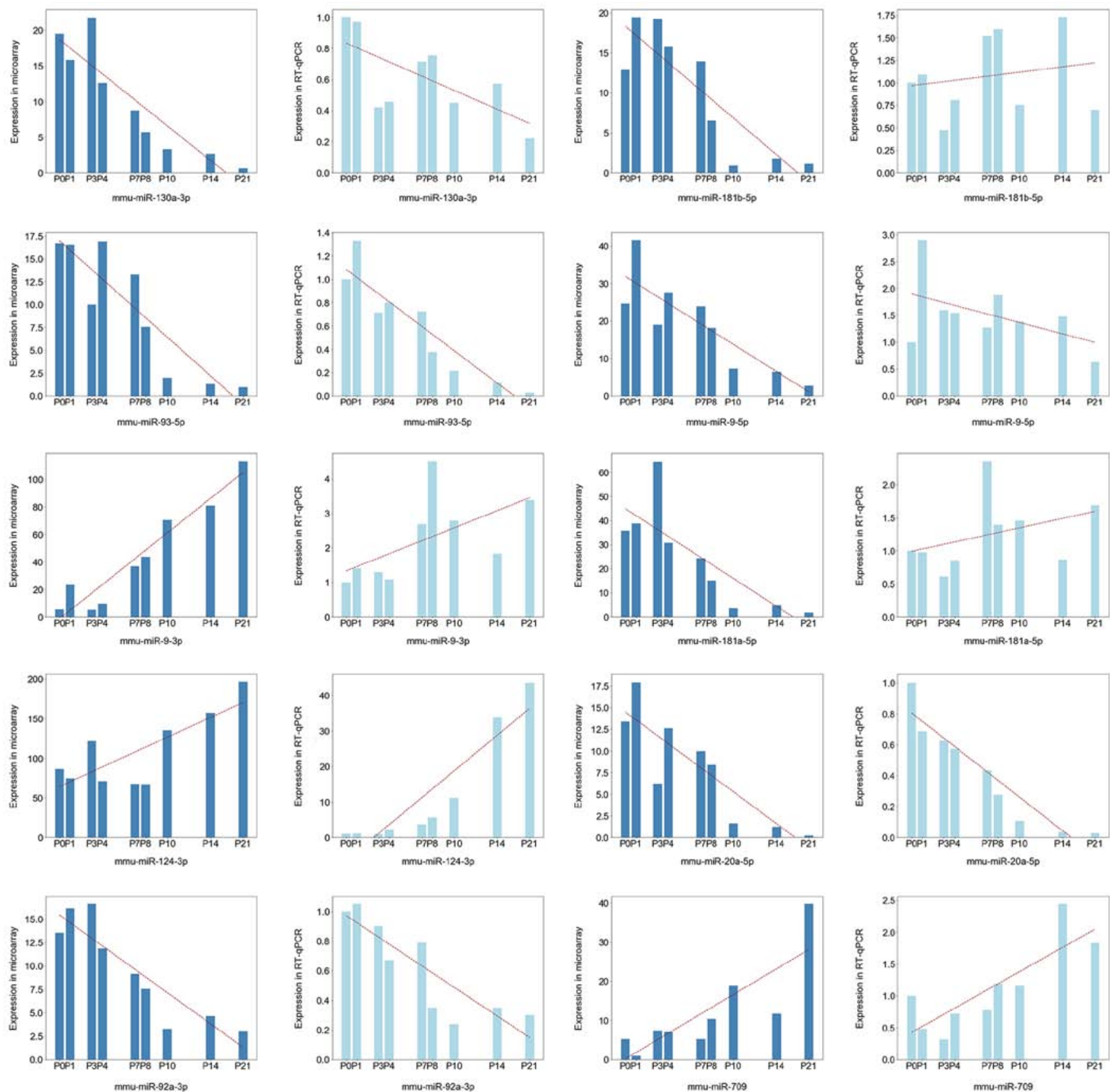

Figure 6. Expression of the 10 miRNAs in microarray and RT-qPCR. The bar graph showed the expression of ten DE-miRNAs with significant enrichment in GO and KEGG analyses. The dark blue bar and the light blue bar indicated the expression of each corresponding miRNA in microarray and RT-qPCR, respectively. The red dashed line represented fitted regression line in each graph. Apart from miR-181a-5p and miR-181b-5p, PCR data of ten remaining miRNAs demonstrated similar trends compared with microarray results. miRNA/miR, microRNA; RT-qPCR, reverse transcription-quantitative polymerase chain reaction; DE, differentially expressed; mmu, mouse; GO, Gene Ontology; KEGG, Kyoto Encyclopedia of Genes and Genomes.

miR-181a-5p and miR-181b-5p are highly homologous and share similar predicted target genes. Therefore, in the present study, these 2 miRNAs were considered as miR-181a/b-5p. KEGG analysis revealed that miR-181a/b-5p was enriched in TGF- $\beta$ and MAPK signaling pathways. Carrella et al (33) demonstrated that miR-181a/b is a key factor in the specification and growth of retinal axons in medaka fish and is involved in MAPK/ERK and TGF- $\beta$ signaling. In the microarray data in the present study, they had similar expression patterns with a correlation coefficient $>0.9$ and were undetectable after P10. However, RT-qPCR in the present study revealed that $\mathrm{miR}-181 \mathrm{a} / \mathrm{b}-5 \mathrm{p}$ exhibited minimal changes during retinal development. A previous study used RNA in situ hybridization to demonstrate that miR-181a was strongly expressed in both postnatal and adult mouse retina (34).

miR-92a-3p and miR-20a-5p are members of the mir-17-92 cluster, while miR-93-5p is a paralog. In the present study, these three miRNAs shared similar expression pattern. Previous studies have revealed associations between the aforementioned three miRNAs and angiogenesis (35-37). Blood vessel growth in a mouse model of limb ischemia and myocardial infarction is enhanced following inhibition of miR-92a-3p (35). miR-20a is shown to target MKK3 and to regulate the migration and angiogenesis of human endothelial 


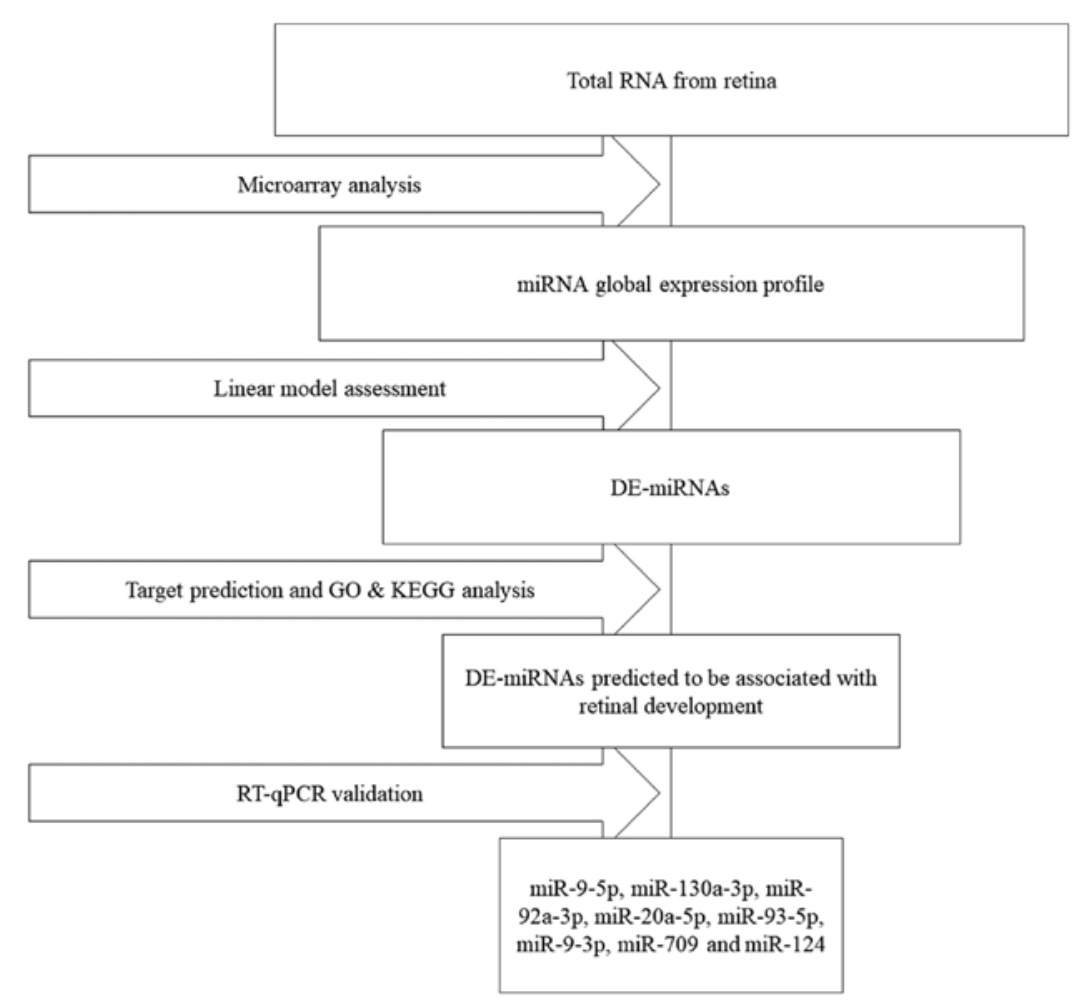

Figure 7. Schematic diagram of the present study. miRNA/miR, microRNA; DE, differentially expressed; GO, Gene Ontology; KEGG, Kyoto Encyclopedia of Genes and Genomes; RT-qPCR, reverse transcription-quantitative polymerase chain reaction.

cells in vitro (36). Fang et al (37) demonstrated that miR-93 promotes angiogenesis in a human breast carcinoma cell line by targeting LATS2. However, to the best of the authors' knowledge, in vivo studies investigating the effect of these three miRNAs on retinal development under normal conditions have not previously been performed.

Functional studies of miR-709, miR-125a-5p, miR-129-1-3p, miR-130a-3p and miR-378a-3p on retinal development are lacking. The present authors are not aware of any studies identifying that miR-709 is associated with angiogenesis or neurogenesis. It has been reported that miR-125 was linked to neurogenesis by promoting cell differentiation in mice and humans (38-40). La Torre et al (41) demonstrated that miR-125 is one of the key regulators of retinal progenitors and that overexpression of miR-125 increases progenitor progression in Dicer-CKO retinas in mice. miR-129 has been revealed to be highly expressed at the early stages of development in the Xenopus retina (42). Furthermore, miR-129-1 suppresses angiogenesis in human umbilical vein endothelial cells (43). miR-130a regulates neurodevelopment by inhibiting neurite outgrowth in rat brains (44). Previous studies have suggested that miR-378a-3p may promote tumor angiogenesis $(45,46)$. However, apart from miR-709, KEGG analysis in the present study did not identify enrichment of miR-378a-3p, miR-129-1-3p or miR-125a-5p.

The enriched pathways identified in the present study are all associated with neurodevelopment or angiogenesis. Previous studies have reported that the PI3K/AKT/mTOR pathway can promote the growth of neural stem cells in mammal $(47,48)$. In vivo, the PI3K/AKT/mTOR pathway has an important role in mammalian brain development, under both physiological and pathological conditions (49-51). The MAPK signaling pathway is highly conserved and is associated with various cellular functions (52). It has been reported that, together with the PI3K/AKT pathway, the MAPK signaling pathway exhibits neuroprotective effects in neurons in rat retina (53) and increases their proliferation and transdifferentiation (54). The FOXO family of transcription factions serves essential roles in regulating the expression of genes. FOXO shows a temporal expression pattern in the developing zebra fish retina (55) and may promote angiogenesis by increasing the metabolism and proliferation of endothelial cells (56). Neurotrophin signaling and the axon guidance pathway are involved in the formation of the neuronal network. In the mouse retina, these 2 pathways regulate survival, differentiation and cytoskeletal organization of neural cells (57) and are also associated with other pathways. The axon guidance factor netrin- 4 increases angiogenesis and the neurotrophin brain-derived neurotrophic factor promotes the maturation of neurons in mammals, both by increasing activation of MAPK $(58,59)$.

TGF- $\beta$ signaling pathway regulates several cellular processes, including proliferation, apoptosis, differentiation and migration. Studies have demonstrated that this pathway regulates the survival and growth of neurons and is associated with angiogenesis in both physiological and pathological conditions in the mammalian retina (33,60-63). Focal adhesions serve important roles in biological processes. It has been reported that focal adhesions are associated with angiogenesis and neuron growth in humans and mice $(64,65)$. Researchers have found that focal adhesion-associated proteins and signaling were necessary for retinal development in Xenopus and Drosophila $(66,67)$. The overexpression of focal adhesion kinase, a focal adhesion-associated protein kinase, contributed to retinal angiogenesis in oxygen-induced retinopathy mice (68). 
PI3K, AKT, PTEN, MAPK1, SOS, S1PR1, BCL2L11, TGFBR $1 / 2$ and ITGA/ITGAB serve essential roles in the enriched pathways identified in the present study and interact with the identified DE-miRNAs. PI3K and AKT are key factors in the majority of the enriched pathways, including PI3K/AKT/mTOR, MAPK, FOXO and neurotrophin signaling, as well as the focal adhesion pathway. PTEN, MAPK1 and SOS are important secondary effectors that participate in a number of signaling pathways $(47,69)$. A previous study reported that S1PR1 is associated with vascular growth and development in mouse (70). Furthermore, Chae et al (71) demonstrated that S1PR1 promoted mouse limb morphogenesis. BCL2L11 acts as an apoptotic activator (72). S1PR1 and BCL2L11 are both downstream effectors, while TGFBR1/2 and ITGA/ITGB are upstream regulators that coordinate a series of downstream effects.

In conclusion, the present study identified several key DE-miRNAs using a linear model. Furthermore, the target genes and pathways that were identified may serve crucial roles in mouse retinal development. Following RT-qPCR validation, eight miRNAs were identified associated with retinal development. These were: miR-9-5p, miR-130a-3p, miR-92a-3p, miR-20a-5p, miR-93-5p, miR-9-3p, miR-709 and miR-124. The results obtained in the present study may provide the groundwork for further experiments.

\section{Acknowledgements}

Not applicable.

\section{Funding}

The present study was supported by grants from the National Natural Science Foundation of China (grant no. 81770971) and the Natural Science Foundation of Guangdong Province (grant no. 2017A030313787) to YL.

\section{Availability of data and materials}

The datasets generated and analyzed during the current study are available in the GEO repository (https://www.ncbi.nlm. nih.gov/geo/query/acc.cgi?acc=GSE115581).

\section{Authors' contributions}

YW performed the bioinformatics analysis and contributed to writing manuscript. XW, RL and DC performed the microarray and RT-qPCR experiments. YJ and JP assisted with the bioinformatics analysis. YL designed the study. All authors read and approved the final manuscript.

\section{Ethics approval and consent to participate}

The procedures for care and use of animals were approved by the Ethics Committee of the Sun Yat-Sen University, Zhongshan Ophthalmic Center (ethical approval no. 2017-069).

\section{Patient consent for publication}

Not applicable.

\section{Competing interests}

The authors declare that they have no competing interests.

\section{References}

1. Suárez Y, Fernández-Hernando C, Yu J, Gerber SA, Harrison KD, Pober JS, Iruela-Arispe ML, Merkenschlager M and Sessa WC: Dicer-dependent endothelial microRNAs are necessary for postnatal angiogenesis. Proc Natl Acad Sci USA 105: 14082-14087, 2008.

2. Zamore PD and Haley B: Ribo-gnome: The big world of small RNAs. Science 309: 1519-1524, 2005.

3. Leonardo TR, Schultheisz HL, Loring JF and Laurent LC: The functions of microRNAs in pluripotency and reprogramming. Nat Cell Biol 14: 1114-1121, 2012.

4. de Chevigny A, Coré N, Follert P, Gaudin M, Barbry P, Béclin C and Cremer H: miR-7a regulation of Pax6 controls spatial origin of forebrain dopaminergic neurons. Nat Neurosci 15: 1120-1126, 2012.

5. Surzenko N, Crowl T, Bachleda A, Langer L and Pevny L: SOX2 maintains the quiescent progenitor cell state of postnatal retinal Muller glia. Development 140: 1445-1456, 2013.

6. Damiani D, Alexander JJ, O'Rourke JR, McManus M, Jadhav AP, Cepko CL, Hauswirth WW, Harfe BD and Strettoi E: Dicer inactivation leads to progressive functional and structural degeneration of the mouse retina. J Neurosci 28: 4878-4887, 2008.

7. Lin S and Gregory RI: MicroRNA biogenesis pathways in cancer. Nat Rev Cancer 15: 321-333, 2015.

8. Rupaimoole R and Slack FJ: MicroRNA therapeutics: Towards a new era for the management of cancer and other diseases. Nat Rev Drug Discov 16: 203-222, 2017.

9. Karali M, Peluso I, Marigo V and Banfi S: Identification and characterization of microRNAs expressed in the mouse eye. Invest Ophthalmol Vis Sci 48: 509-515, 2007.

10. Hackler L Jr, Wan J, Swaroop A, Qian J and Zack DJ: MicroRNA profile of the developing mouse retina. Invest Ophthalmol Vis Sci 51: 1823-1831, 2010

11. Stahl A, Connor KM, Sapieha P, Chen J, Dennison RJ, Krah NM, Seaward MR, Willett KL, Aderman CM, Guerin KI, et al: The mouse retina as an angiogenesis model. Invest Ophthalmol Vis Sci 51: 2813-2826, 2010.

12. Fan WJ, Li X, Yao HL, Deng JX, Liu HL, Cui ZJ, Wang Q, Wu P and Deng JB: Neural differentiation and synaptogenesis in retinal development. Neural Regen Res 11: 312-318, 2016.

13. Agarwal V, Bell GW, Nam JW and Bartel DP: Predicting effective microRNA target sites in mammalian mRNAs. eLife 4: 4, 2015.

14. Wong $\mathrm{N}$ and Wang X: miRDB: An online resource for microRNA target prediction and functional annotations. Nucleic Acids Res 43: D146-D152, 2015.

15. Ashburner M, Ball CA, Blake JA, Botstein D, Butler H, Cherry JM, Davis AP, Dolinski K, Dwight SS, Eppig JT, et al; The Gene Ontology Consortium: Gene ontology: Tool for the unification of biology. Nat Genet 25: 25-29, 2000.

16. The Gene Ontology Consortium: Expansion of the Gene Ontology knowledgebase and resources. Nucleic Acids Res 45: D331-D338, 2017.

17. Ogata H, Goto S, Sato K, Fujibuchi W, Bono H and Kanehisa M: KEGG: Kyoto Encyclopedia of Genes and Genomes. Nucleic Acids Res 27: 29-34, 1999.

18. Huang W, Sherman BT and Lempicki RA: Bioinformatics enrichment tools: Paths toward the comprehensive functional analysis of large gene lists. Nucleic Acids Res 37: 1-13, 2009.

19. Huang W, Sherman BT and Lempicki RA: Systematic and integrative analysis of large gene lists using DAVID bioinformatics resources. Nat Protoc 4: 44-57, 2009.

20. Livak KJ and Schmittgen TD: Analysis of relative gene expression data using real-time quantitative PCR and the 2(-Delta Delta C(T)) method. Methods 25: 402-408, 2001.

21. Larionov A, Krause A and Miller W: A standard curve based method for relative real time PCR data processing. BMC Bioinformatics 6: 62, 2005.

22. Aubert M, Chaplain MA, McDougall SR, Devlin A and Mitchell CA: A continuum mathematical model of the developing murine retinal vasculature. Bull Math Biol 73: 2430-2451, 2011 
23. Xu S, Witmer PD, Lumayag S, Kovacs B and Valle D: MicroRNA (miRNA) transcriptome of mouse retina and identification of a sensory organ-specific miRNA cluster. J Biol Chem 282: 25053-25066, 2007.

24. Lavker RM and Ryan DG: MicroRNAs of the mammalian eye display distinct and overlapping tissue specificity. Invest Ophthalmol Vis Sci 47: 5410-5410, 2006.

25. Shi Z, Chen Q, Li C, Wang L, Qian X, Jiang C, Liu X, Wang X, $\mathrm{Li} \mathrm{H}$, Kang C, et al: MiR-124 governs glioma growth and angiogenesis and enhances chemosensitivity by targeting R-Ras and N-Ras. Neuro Oncol 16: 1341-1353, 2014.

26. Silber J, Lim DA, Petritsch C, Persson AI, Maunakea AK, Yu M, Vandenberg SR, Ginzinger DG, James CD, Costello JF, et al: miR-124 and miR-137 inhibit proliferation of glioblastoma multiforme cells and induce differentiation of brain tumor stem cells. BMC Med 6: 14, 2008.

27. He Y, Li HB, Li X, Zhou Y, Xia XB and Song WT: MiR-124 promotes the growth of retinal ganglion cells derived from Müller cells. Cell Physiol Biochem 45: 973-983, 2018.

28. Baudet ML, Zivraj KH, Abreu-Goodger C, Muldal A, Armisen J, Blenkiron C, Goldstein LD, Miska EA and Holt CE: miR-124 acts through CoREST to control onset of Sema3A sensitivity in navigating retinal growth cones. Nat Neurosci 15: 29-38, 2011.

29. Yoo AS, Sun AX, Li L, Shcheglovitov A, Portmann T, Li Y, Lee-Messer C, Dolmetsch RE, Tsien RW and Crabtree GR: MicroRNA-mediated conversion of human fibroblasts to neurons. Nature 476: 228-231, 2011.

30. Kania EE, Carvajal-Moreno J, Hernandez VA, English A, Papa JL, Shkolnikov N, Ozer HG, Yilmaz AS, Yalowich JC and Elton TS: hsa-miR-9-3p and hsa-miR-9-5p as post-transcriptional modulators of DNA topoisomerase II $\alpha$ in human leukemia K562 cells with acquired resistance to etoposide. Mol Pharmacol 97: 159-170, 2020

31. Sim SE, Lim CS, Kim JI, Seo D, Chun H, Yu NK, Lee J, Kang SJ, Ko HG, Choi JH, et al: The brain-enriched MicroRNA miR-9-3p regulates synaptic plasticity and memory. J Neurosci 36 : $8641-8652,2016$

32. Coolen M, Katz S and Bally-Cuif L: miR-9: A versatile regulator of neurogenesis. Front Cell Neurosci 7: 220, 2013.

33. Carrella S, Barbato S, D'Agostino Y, Salierno FG, Manfredi A Banfi S and Conte I: TGF- $\beta$ controls miR-181/ERK regulatory network during retinal axon specification and growth. PLoS One 10: e0144129, 2015.

34. Karali M, Persico M, Mutarelli M, Carissimo A, Pizzo M, Singh Marwah V, Ambrosio C, Pinelli M, Carrella D, Ferrari S, et al: High-resolution analysis of the human retina miRNome reveals isomiR variations and novel microRNAs. Nucleic Acids Res 44: 1525-1540, 2016

35. Bonauer A, Carmona G, Iwasaki M, Mione M, Koyanagi M, Fischer A, Burchfield J, Fox H, Doebele C, Ohtani K, et al: MicroRNA-92a controls angiogenesis and functional recovery of ischemic tissues in mice. Science 324: 1710-1713, 2009.

36. Pin AL, Houle F, Guillonneau M, Paquet ER, Simard MJ and Huot J: miR-20a represses endothelial cell migration by targeting MKK3 and inhibiting p38 MAP kinase activation in response to VEGF. Angiogenesis 15: 593-608, 2012.

37. Fang L, Du WW, Yang W, Rutnam ZJ, Peng C, LiH, O'Malley YQ, Askeland RW, Sugg S, Liu M, et al: MiR-93 enhances angiogenesis and metastasis by targeting LATS2. Cell Cycle 11: 4352-4365, 2012.

38. Akerblom M, Petri R, Sachdeva R, Klussendorf T, Mattsson B, Gentner B and Jakobsson J: microRNA-125 distinguishes developmentally generated and adult-born olfactory bulb interneurons. Development 141: 1580-1588, 2014.

39. Boissart C, Nissan X, Giraud-Triboult K, Peschanski M and Benchoua A: miR-125 potentiates early neural specification of human embryonic stem cells. Development 139: 1247-1257, 2012.

40. Le MT, Xie H, Zhou B, Chia PH, Rizk P, Um M, Udolph G, Yang H, Lim B and Lodish HF: MicroRNA-125b promotes neuronal differentiation in human cells by repressing multiple targets. Mol Cell Biol 29: 5290-5305, 2009.

41. La Torre A, Georgi S and Reh TA: Conserved microRNA pathway regulates developmental timing of retinal neurogenesis. Proc Natl Acad Sci USA 110: E2362-E2370, 2013.

42. Decembrini S, Bressan D, Vignali R, Pitto L, Mariotti S, Rainaldi G, Wang X, Evangelista M, Barsacchi G and Cremisi F: MicroRNAs couple cell fate and developmental timing in retina. Proc Natl Acad Sci USA 106: 21179-21184, 2009.
43. Soufi-Zomorrod M, Hajifathali A, Kouhkan F, Mehdizadeh M, Rad SM and Soleimani M: MicroRNAs modulating angiogenesis: miR-129-1 and miR-133 act as angio-miR in HUVECs. Tumour Biol 37: 9527-9534, 2016.

44. Zhang Y, Chen M, Qiu Z, Hu K, McGee W, Chen X, Liu J, Zhu L and Wu JY: MiR-130a regulates neurite outgrowth and dendritic spine density by targeting MeCP2. Protein Cell 7: 489-500, 2016.

45. Lee DY, Deng Z, Wang CH and Yang BB: MicroRNA-378 promotes cell survival, tumor growth, and angiogenesis by targeting SuFu and Fus-1 expression. Proc Natl Acad Sci USA 104: 20350-20355, 2007.

46. Chan JK, Kiet TK, Blansit K, Ramasubbaiah R, Hilton JF, Kapp DS and Matei D: MiR-378 as a biomarker for response to anti-angiogenic treatment in ovarian cancer. Gynecol Oncol 133: 568-574, 2014

47. Rafalski VA and Brunet A: Energy metabolism in adult neural stem cell fate. Prog Neurobiol 93: 182-203, 2011.

48. Zhang X, He X, Li Q, Kong X, Ou Z, Zhang L, Gong Z, Long D, Li J, Zhang M, et al: PI3K/AKT/mTOR signaling mediates valproic acid-induced neuronal differentiation of neural stem cells through epigenetic modifications. Stem Cell Reports 8: 1256-1269, 2017

49. Adams HH, Hibar DP, Chouraki V, Stein JL, Nyquist PA, Rentería ME, Trompet S, Arias-Vasquez A, Seshadri S, Desrivières $\mathrm{S}$, et al: Novel genetic loci underlying human intracranial volume identified through genome-wide association. Nat Neurosci 19: 1569-1582, 2016.

50. Peltier J, O'Neill A and Schaffer DV: PI3K/Akt and CREB regulate adult neural hippocampal progenitor proliferation and differentiation. Dev Neurobiol 67: 1348-1361, 2007.

51. Hevner RF: Brain overgrowth in disorders of RTK-PI3K-AKT signaling: A mosaic of malformations. Semin Perinatol 39: $36-43,2015$.

52. Zhang $\mathrm{W}$ and Liu HT: MAPK signal pathways in the regulation of cell proliferation in mammalian cells. Cell Res 12: 9-18, 2002.

53. Nakazawa T, Tamai M and Mori N: Brain-derived neurotrophic factor prevents axotomized retinal ganglion cell death through MAPK and PI3K signaling pathways. Invest Ophthalmol Vis Sci 43: 3319-3326, 2002

54. Galy A, Néron B, Planque N, Saule S and Eychène A: Activated MAPK/ERK kinase (MEK-1) induces transdifferentiation of pigmented epithelium into neural retina. Dev Biol 248: 251-264, 2002

55. Lin SJ, Chiang MC, Shih HY, Chiang KC and Cheng YC: Spatiotemporal expression of foxo4, foxo6a, and foxo6b in the developing brain and retina are transcriptionally regulated by PI3K signaling in zebrafish. Dev Genes Evol 227: 219-230, 2017.

56. Wilhelm K, Happel K, Eelen G, Schoors S, Oellerich MF, Lim R, Zimmermann B, Aspalter IM, Franco CA, Boettger T, et al: FOXO1 couples metabolic activity and growth state in the vascular endothelium. Nature 529: 216-220, 2016.

57. Llamosas MM, Cernuda-Cernuda R, Huerta JJ, Vega JA and García-Fernández JM: Neurotrophin receptors expression in the developing mouse retina: An immunohistochemical study. Anat Embryol (Berl) 195: 337-344, 1997.

58. Lange J, Yafai Y, Noack A, Yang XM, Munk AB, Krohn S, Iandiev I, Wiedemann P, Reichenbach A and Eichler W: The axon guidance molecule Netrin-4 is expressed by Müller cells and contributes to angiogenesis in the retina. Glia 60: 1567-1578, 2012.

59. Rohrer B, Korenbrot JI, LaVail MM, Reichardt LF and Xu B: Role of neurotrophin receptor TrkB in the maturation of rod photoreceptors and establishment of synaptic transmission to the inner retina. J Neurosci 19: 8919-8930, 1999.

60. Wang X, Abraham S, McKenzie JAG, Jeffs N, Swire M, Tripathi VB, Luhmann UF, Lange CAK, ZhaiZ, Arthur HM, et al: LRG1 promotes angiogenesis by modulating endothelial TGF- $\beta$ signalling. Nature 499: 306-311, 2013.

61. Zhao M, Hu Y, Jin J, Yu Y, Zhang S, Cao J, Zhai Y, Wei R, Shou J, Cai $\mathrm{W}$, et al: Interleukin 37 promotes angiogenesis through TGF- $\beta$ signaling. Sci Rep 7: 6113, 2017.

62. Bialas AR and Stevens B: TGF- $\beta$ signaling regulates neuronal C1q expression and developmental synaptic refinement. Nat Neurosci 16: 1773-1782, 2013.

63. Braunger BM, Pielmeier S, Demmer C, Landstorfer V, Kawall D, Abramov N, Leibinger M, Kleiter I, Fischer D, Jägle H, et al: TGF- $\beta$ signaling protects retinal neurons from programmed cell death during the development of the mammalian eye. J Neurosci 33: 14246-14258, 2013. 
64. Chacón MR, Navarro AI, Cuesto G, del Pino I, Scott R, Morales $\mathrm{M}$ and Rico B: Focal adhesion kinase regulates actin nucleation and neuronal filopodia formation during axonal growth. Development 139: 3200-3210, 2012.

65. Zhao X and Guan JL: Focal adhesion kinase and its signaling pathways in cell migration and angiogenesis. Adv Drug Deliv Rev 63: 610-615, 2011.

66. Li M and Sakaguchi DS: Expression patterns of focal adhesion associated proteins in the developing retina. Dev Dyn 225: 544-553, 2002.

67. Xie X, Gilbert M, Petley-Ragan L and Auld VJ: Loss of focal adhesions in glia disrupts both glial and photoreceptor axon migration in the Drosophila visual system. Development 141: 3072-3083, 2014.

68. Kornberg LJ, Shaw LC, Spoerri PE, Caballero S and Grant MB: Focal adhesion kinase overexpression induces enhanced pathological retinal angiogenesis. Invest Ophthalmol Vis Sci 45: 4463-4469, 2004
69. Margolis B and Skolnik EY: Activation of Ras by receptor tyrosine kinases. J Am Soc Nephrol 5: 1288-1299, 1994.

70. Lee MJ, Thangada S, Claffey KP, Ancellin N, Liu CH, Kluk M, Volpi M, Sha'afi RI and Hla T: Vascular endothelial cell adherens junction assembly and morphogenesis induced by sphingosine-1-phosphate. Cell 99: 301-312, 1999.

71. Chae SS, Paik JH, Allende ML, Proia RL and Hla T: Regulation of limb development by the sphingosine 1-phosphate receptor S1p1/EDG-1 occurs via the hypoxia/VEGF axis. Dev Biol 268: 441-447, 2004.

72. O'Connor L, Strasser A, O'Reilly LA, Hausmann G, Adams JM, Cory S and Huang DC: Bim: A novel member of the Bcl-2 family that promotes apoptosis. EMBO J 17: 384-395, 1998.

(i) (9) This work is licensed under a Creative Commons Attribution-NonCommercial-NoDerivatives 4.0 International (CC BY-NC-ND 4.0) License. 